\title{
PENGARUH VARIASI PENGAKTIFAN DELAY BOLUS TRIGGERING TERHADAP DOSIS RADIASI PADA PEMERIKSAAN CT SCAN THORAX DI INSTALASI RADIOLOGI RSUD DR.MOEWARDI
}

\author{
THE INFLUENCE OF BOLUS TRIGGERING ACTIVATION DELAY \\ TO RADIATION DOSE AT CT SCAN EXAMINATION OF THE THORAX \\ IN RADIOLOGY OF Dr. MOEWARDI HOSPITAL
}

\author{
Rini Indrati ${ }^{1)}$, Mariyatun ${ }^{2)}$, Andrey Nino Kurniawan ${ }^{3)}$ \\ ${ }^{1,3)}$ Health Polytechnics of Semarang-Indonesia \\ ${ }^{2)}$ Technologist in Moewardi Hospital \\ e-mail : rini_indrati@yahoo.com
}

\begin{abstract}
Background : Examination of Thorax CT Scan in RSUD Dr.Moewardi is always conducted using bolus triggering technique, where delay of bolus triggering activation done to vary value between 5 - 10 second after contrast media administration using automatic injector with the reason to lessen radiation dose. Purpose of this research is to know influence of bolus triggering activation delay to radiation dose as well as to find out maximal delay value of bolus triggering activation delay which can be conducted at CT Scan Thorax examination.

Methods : This research is experimental method. Data were collected from the observations and the direct examinations on the monitor screen using the CTDIvol dose calculation software. This research is carried out by recording the changes radiation dose value on CTDIvol by changing the value of bolus triggering activation delay from $0,2,4,6,8,10,12$ and 14 second. Data were analyzed using regression test.

Results : The result shows that correlation between bolus triggering activation delay towards radiation dose with $r=0,970, p$ value $<0,001$ and $\mathrm{R}^{2}=0,940$. The meaning $94 \%$ radiation dose influenced by bolus triggering activation. Delay with regresi equation, $\mathrm{Y}=308,252-$ $18,821 \mathrm{DT}$, showing each every increase of delay bolus triggering activation delay equal to 1 second will influence to descend dose radiasi equal to $18,821 \mathrm{mGy}$.

Conclusion : Maximum delay to activated bolus triggering is 17 second.
\end{abstract}

Keywords : delay, bolus triggering, radiation dose, scanning, CTDIvol

\section{PENDAHULUAN}

CT scan merupakan modalitas imaging yang memberikan kualitas resolusi gambar yang baik meskipun juga memberikan dosis radiasi yang besar. Dosis radiasi pada $\mathrm{CT}$ scan dapat ditekan dengan mengatur parameter-parameter CT scan yang tepat (Sarkar dkk, 2005).

CT Scan Thoraks adalah teknik pemeriksaan secara radiologi untuk mendapatkan informasi anatomi dan kelainankelainan yang ada di rongga thoraks termasuk mediastinum. Selain informasi anatomi, kelainan yang dapat dilakukan dengan pemeriksaan CT Scan thoraks atau mediastinum adalah Tumor, Aneurisma, Abses, Lesi pada hilius atau mediastinal dan pembedahan Aorta (Bontrager,2001).

Kontras intravena pada CT Scan thorak, digunakan untuk menampilkan massa hilar, lymphoma dan massa kardiak dengan penyangatan / enhancement sebaik pada aorta dan pembuluh darah yang lain yang ada di thorak (Neseth, 2000). Penyangatan sistem vaskular dapat digunakan untuk lokalisasi anatomi, membedakan vessel dari massa, menentukan perluasan vaskular atau invasi oleh tumor, menaksir penyakit vaskular lain seperti aneurisma, stenosis atau penurunan integritas vaskular (Serram, 2001).

Pemasukkan media kontras pada CT scan thorax membutuhkan power injector terprogram. Pemasukkan media kontras dilakukan menggunakan injektor otomatis 2 syringe (Dual Head Injector) sebanyak 60-120 ml media kontras dengan injection rate 1,5-3 ml/s, duration injection lama (> 30 s), scan delay 20 - 30 s dengan konsentrasi media kontras 300 $\mathrm{mgI} / \mathrm{l}(20-30 \mathrm{mgI})$. Scanning menggunakan bolus triggering dengan penempatan ROI pada pembuluh darah dengan trigger level 100 HU. Selama media kontras dimasukkan, pesawat CT scan melakukan serangkaian scan/scan monitoring di daerah ROI untuk memantau nilai HU yang telah tercapai. Scanning penuh dilakukan $2-8$ detik setelah batas HU tercapai, tergantung jenis scanner/pesawat CT Scan, jarak longitudinal dari daerah monitoring ROI dan batas awal area scanning (D.Fleischmann, 2006). Menurut Lipson (2006) nilai delay before monitoring adalah 20 detik dengan trigger value (ROI) 200 pada aorta desenden. Pemeriksaan CT Scan Thorax di instalasi Radiologi RSUD Dr.Moewardi menggunakan pesawat CT Scan 64 slice dan media kontras dengan konsentrasi $300 \mathrm{mgI} / \mathrm{l}$ sebanyak $60-80 \mathrm{ml}$ dengan injection rate $2,5-3 \mathrm{ml} / \mathrm{s}$. Penempatan ROI pada aorta desenden dengan HU (Housefield Unit) level 180, pengaktifan bolus triggering dilakukan antara 5-10 detik setelah media kontras masuk, dengan alasan untuk mengurangi dosis radiasi. Semakin banyak scan monitoring dilakukan dosis radiasi yang dihasilkan juga lebih besar. Penelitian ini bertujuan untuk mengetahui pengaruh variasi delay pengaktifan bolus triggering terhadap dosis radiasi dan mengetahui delay maksimal yang masih dapat dilakukan pada pemeriksaan CT Scan Thorax. 


\section{METODE}

Ini merupakan penelitian eksperimen, Data diambil secara observasional. Variasi Delay yang digunakan adalah $0,2,4,6,8,10,12$ dan 14 detik.

Dosis radiasi diukur dengan menggunakan Computed Tomography Dose Index volume (CTDIvol). Sampel pasien terdiri dari 14 perempuan dan 10 laki-laki berusia $40-76$ tahun sebanyak 21 orang dan berusia $<30$ tahun sebanyak 3 orang, dengan klinis suspek keganasan sebanyak $75 \%$ sedangkan 25\% lainnya dengan klinis lain seperti efusi pleura dan nodul paru. Masing-masing variasi delay pengaktifan bolus triggering dilakukan pada 3 pasien sehingga didapatkan 24 nilai dosis radiasi.

Analis data dilakukan dengan menggunakan uji regresi untuk mengetahui besarnya pengaruh antara variasi delay pengaktifan bolus triggering terhadap dosis radiasi

\section{HASIL}

Setelah dilakukan pengukuran dosis radiasi (CTDIvol) pada hasil scanning CT Scan Thorax dengan variasi nilai delay pengatifan bolus triggering diperoleh nilai dosis radiasi seperti pada tabel 1 .

Tabel 1. CTDIvol pada variasi delay pengaktifan bolus triggering

\begin{tabular}{cc}
\hline $\begin{array}{c}\text { Delay Pengaktifan } \\
\text { Bolus Triggering }\end{array}$ & $\begin{array}{c}\text { CTDI vol } \\
\text { (mGy) }\end{array}$ \\
\hline 0 detik & 276,43 \\
2 detik & 280,63 \\
4 detik & 262,17 \\
6 detik & 217,03 \\
8 detik & 155,03 \\
10 detik & 84,47 \\
12 detik & 91,30 \\
14 detik & 44,97 \\
\hline
\end{tabular}
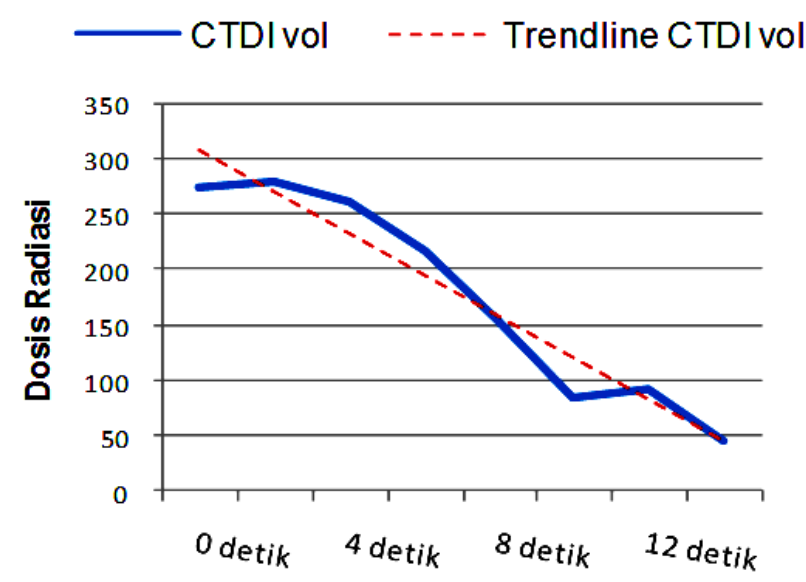

Gambar 1. Grafik Pengaruh perubahan delay pengaktifan bolus triggering terhadap dosis radiasi (CTDIvol)

Dosis Radiasi/CTDIvol yang penulis tampilkan merupakan dosis radiasi/CTDIvol total dari keseluruhan scanning yaitu : Helical CT yaitu scanning penuh pre kontras/non kontras; Normal CT yaitu scanning satu slice, untuk penempatan ROI; Dinamic CT yaitu serangkaian scan monitoring; Helical $C T$ yaitu scanning penuh kedua post kontras

Tabel 2. Hasil analisa data menggunakan analisa regresi

\begin{tabular}{lr}
\hline \multicolumn{1}{c}{ Uji Statistik } & \multicolumn{1}{c}{ Nilai } \\
\hline Mean & 176,50 \\
$p$ value & $<0,001$ \\
$\mathrm{R}^{2}$ & 0,940 \\
Koefisisen Korelasi (r) & $-0,970$ \\
$\mathrm{a}$ (konstanta) & 308,252 \\
$\mathrm{~b}$ (koefisien regresi) & $-18,821$ \\
\hline
\end{tabular}

Perubahan dosis radiasi yang disebabkan variasi delay pengaktifan bolus triggering menunjukkan bahwa semakin besar nilai delay pengaktifan bolus triggering akan menyebabkan semakin kecil dosis radiasi yang dihasilkan. Tren penurunan nilai dosis radiasi tersebut dapat dilihat pada gambar 1.

Tabel 3. Data waktu mulai melakukan scanning

\begin{tabular}{cccc}
\hline No. & $\begin{array}{c}\text { Delay Bolus } \\
\text { Triggering }\end{array}$ & $\begin{array}{c}\text { Rata-rata } \\
\text { Scan Time }\end{array}$ & $\begin{array}{c}\text { Delay } \\
\text { maksimal }\end{array}$ \\
\hline 1 & 0 & 27,00 & 17,00 \\
2 & 2 & 27,00 & 17,00 \\
3 & 4 & 27,67 & 17,67 \\
4 & 6 & 29,33 & 19,33 \\
5 & 8 & 27,00 & 17,00 \\
6 & 10 & 26,33 & 16,33 \\
7 & 12 & 28,00 & 18,00 \\
8 & 14 & 25,33 & 15,33 \\
\hline \multicolumn{4}{c}{ Mean delay maksimal } \\
\hline \multicolumn{4}{c}{$p$ value } \\
\hline \multicolumn{4}{c}{}
\end{tabular}

\section{DISKUSI}

Uji regresi pada tingkat kepercayaan 95\% menunjukkan $p$ value $<0,001(<0,05)$ berarti ada pengaruh antara variasi delay pengaktifan bolus triggering terhadap dosis radiasi. Dengan koefisien determinasi $\left(R^{2}\right)=0,940$ menunjukkan bahwa dosis radiasi yang dihasilkan $94 \%$ dipengaruhi oleh delay pengaktifan bolus triggering sedangkan yang $6 \%$ dipengaruhi oleh faktor-faktor yang lain.

Pada pemeriksaan CT Thorak jika tidak dilakukan delay pengaktifan bolus triggering dosis radiasi (CTDIvol) yang dihasilkan sebesar 308,252 mGy. Jika dilakukan delay pengaktifan bolus triggering maka setiap kenaikan waktu delay bolus triggering sebesar 1 detik akan menyebabkan penurunan dosis radiasi (CTDI vol) sebesar 18,821 mGy.

Pada penelitian ini, walaupun scan parameter yang digunakan sama yaitu sebagai variabel kontrol tetapi waktu dimulainya scan penuh pada masing-masing pasien berbeda. 
Waktu scanning penuh masing-masing pasien dimulai pada detik yang berbeda seperti pada tabel 3 .

Nilai delay maksimal diperoleh dari nilai rata-rata scan penuh dikurangi delay before scan monitoring sebesar 5 detik dan delay before scan sebesar 5 detik. Dari analisa statistik data di atas didapatkan nilai mean/rata-rata adalah 17,20 detik dan hasil uji statistik regresi pada tingkat kepercayaan $95 \%$ menunjukkan $p$ value $<0,437$ (>0,05) yang artinya delay pengaktifan bolus triggering tidak mempengaruhi delay maksimal pada pemeriksaan CT Scan Thorax. Tren pengaruh delay pengaktifan bolus triggering terhadap delay maksimal menunjukkan penurunan yang tidak nyata. Dari hasil di atas dapat diartikan delay maksimal pengaktifan bolus triggering pada pemeriksaan CT Thorax yang masih bisa dilakukan adalah 17,20 detik atau 17 detik.

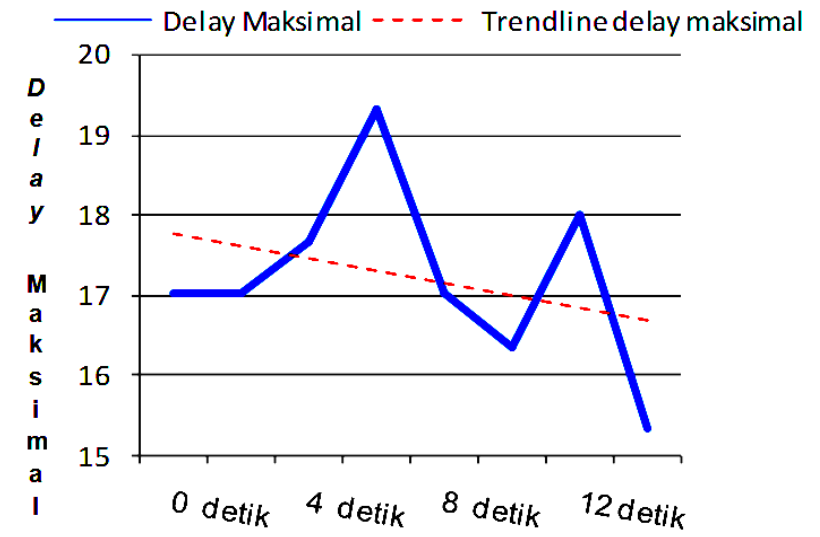

Gambar 2. Grafik pengaruh delay pengaktifan bolus triggering terhadap delay maksimal

Delay pengaktifan bolus triggering mempengaruhi lama scan monitoring yang dilakukan pesawat CT Scan. Semakin tinggi nilai delay pengaktifan bolus triggering akan menurunkan lama scan monitoring yang akan mempengaruhi turunnya dosis radiasi. Pengukuran dosis radiasi pada penelitian ini menggunakan software CTDIvol pesawat $C T$ Scan Toshiba Aquilion 64 slice. Hasil uji pengaruh variasi delay pengaktifan bolus triggering terhadap nilai dosis radiasi dengan menggunakan analisis regresi pada tingkat kepercayaan $95 \%$ menunjukkan $p$ value $<0,001 \quad(<0,05)$ sehingga ada pengaruh antara variasi delay pengaktifan bolus triggering terhadap dosis radiasi pada pemeriksaan CT Scan Thorax di Instalasi Radiologi Rumah Sakit Umum Daerah Dr.Moewardi.

Koefisien determinasi $\left(\mathrm{R}^{2}\right)=0,940$ menunjukkan bahwa dosis radiasi $94 \%$ dipengaruhi oleh delay pengaktifan bolus triggering dan yang $6 \%$ dipengaruhi oleh faktor-faktor lain. Besarnya pengaruh delay pengaktifan bolus triggering terhadap dosis radiasi dikarenakan delay pengaktifan bolus triggering mempengaruhi banyaknya scan monitoring (dinamic scan) yang dilakukan pesawat CT Scan yang akhirnya mempengaruhi dosis radiasi yang dihasilkan. Semakin besar nilai delay pengaktifan bolus triggering semakin sedikit jumlah scan monitoring yang dilakukan sehingga dosis radiasi yang dihasilkan juga semakin kecil.

Dengan persamaan regresi $\mathrm{y}=308,252-18,821 \mathrm{DT}$, dapat diartikan bahwa setiap kenaikan 1 detik delay pengaktifan bolus triggering akan menyebabkan turunnya dosis radiasi sebesar $18,821 \mathrm{mGy}$. Walaupun pada grafik secara nyata menunjukkan tren penurunan dosis radiasi seiring kenaikan nilai pengaktifan bolus triggering akan tetapi grafik yang didapatkan tidak teratur, hal ini disebabkan adanya variasi dari kondisi fisiologis dari pasien yang berbeda. Peneliti sudah berusaha mengontrol faktor flow rate media kontras dengan menggunakan injektor otomatis juga menggunakan jarum abocath dengan ukuran yang sama yaitu 20, dengan asumsi supaya contrast arrival time (Carr) media kontras pasien sama, sehingga pada penggunaan nilai delay pengaktifan bolus triggering yang sama akan didapatkan dosis radiasi yang sama pula.

Akan tetapi kenyataan yang peneliti hadapi di lapangan sangat berbeda. Pada penggunaan delay pengaktifan bolus triggering yang sama didapatkan dosis radiasi yang berbeda. Faktor pasien yang berpengaruh besar terhadap contrast arrival time adalah cardiac output atau cardiovascular circulation time (Bae, 2006). Jika cardiac output berkurang maka sirkulasi media kontras akan lambat sehingga ketercapaian HU level pada ROI aorta desenden juga lambat akibatnya scan monitoring yang terjadi lebih banyak dan dosis radiasi yang dihasilkan juga lebih besar.

Rata-rata scan penuh dimulai yang tercepat pada detik ke-25,33 dan paling lambat pada detik ke-29,33. Jadi scan penuh rata-rata dimulai pada detik ke-27,20. Pesawat CT scan mulai melakukan scan monitoring 5 detik setelah pengaktifan bolus trigger (delay before scan monitoring) dan melakukan scan penuh 5 detik setelah HU level/treshold pada ROI tercapai (delay before scan).

Delay maksimal paling cepat 15,33 detik dan yang terlama 19,33 detik, sedangkan nilai mean delay maksimal adalah 17,20 detik. Dari uji statistik regresi yang dilakukan pada tingkat kepercayaan $95 \%$ didapatkan $p$ value $<0,437$ (> $0,05)$ yang menunjukkan bahwa perubahan nilai delay pengaktifan bolus triggering tidak mempengaruhi delay maksimal yang dapat dilakukan pada pemeriksaan CT Scan Thorax. Jadi delay maksimal yang dapat dilakukan pada pemeriksaan CT Scan Thorax di instalasi radiologi RSUD Dr.Moewardi adalah 17,20 detik. Artinya media kontras dimasukkan lebih dulu menggunakan injektor otomatis selama 17,20 detik kemudian bolus triggering diaktifkan.

Keterbatasan dari penelitian ini adalah kurangnya jumlah pasien pada setiap variasi delay bolus triggering yang digunakan sehingga setiap variasi delay pengaktifan bolus triggering hanya dilakukan pada 3 pasien saja. Tetapi telah dapat memberikan gambaran tentang pengaruh variasi delay pengaktifan

\section{SIMPULAN}


Simpulan dari penelitian ini adalah ada pengaruh antara variasi delay pengaktifan bolus triggering terhadap dosis radiasi pada pemeriksaan CT Scan Thorax pada tingkat kepercayaan 95\% menunjukkanp value $<0,001$ dan $\left(\mathrm{R}^{2}\right)=$ 0,940 dimana $94 \%$ dosis radiasi dipegaruhi oleh delay pengaktifan bolus triggering dan $6 \%$ dipengaruhi faktor lain. Dengan persamaan regresi $\mathrm{Y}=308,252-18,821 \mathrm{DT}$, maka setiap kenaikan waktu delay pengaktifan bolus triggering sebesar 1 detik maka akan mempengaruhi turunnya dosis radiasi sebesar $18,821 \mathrm{mGy}$. Uji regresi pada tingkat kepercayaan 95\% didapat $p$ value $<0,437(>0,05)$ sehingga dapat disimpulkan bahwa variasi/perubahan waktu delay pengaktifan bolus triggering tidak mempengaruhi delay maksimal. Jadi delay maksimal yang dapat dilakukan untuk pemeriksaan CT Scan Thorax adalah 17,20 detik atau 17 detik.

\section{DAFTAR PUSTAKA}

Bontrager, Kenneth L. 2001. Textbook of Radiographic Positioning and Related Anatomy, Fifth Edition. Mosby. United State of America

Bushberg. J. T. 2002. The Essential Physics of Medical Imaging, Second Edition. Philadelphia. USA

Bushong, Stewart. C. 2000. Radiologic Science for Technologists Physics Biology and Protection, Seventh Edition. The CV Mosby Company, Missouri. USA

Castello, P., 1995, Helical/Spiral CT: A Practical Approach, Mc Graw Hill Inc, New York.

Duerk, Jeffrey L. 2002. Principles of Computed Tomography and Magnetic Resonance Imaging. Philadelphia. USA

European Guidelines for MSCT. 2004. Clinical and associated performance parameter for MSCT, March 2004. akses 2 Juni 2013

Fleischmann, D. 2006. Contrast Medium Injection Technique in Multidetector-Row CT of the Thorax, softcover edition. SpringerVerlag Berlin Heidelberg, New York.

Goldman LW. 2007. Principles of CT: Radiation Dose and Image Quality. Journal of Nuclear Medicine Technology Volume 35 Number 4 , p.213-225. Society of Nuclear Medicine.

Hofer, Matthias. 2007. CT Teaching Manual, Second edition. Thieme, Germany.

Hoffmann, Martin H.K. 2009. Contrast Agent Application and Protocols in Mulitislice $C T, 3^{\text {rd }}$ revised edition. Springer-Verlag Berlin Heidelberg, Leipzig Germany.

Jaengsri, Nuttawan, MSc. 2004. CT Protocol, Radiology Departement of Thaksim Hospital. Bangkok.

Lipson, Scott A. 2006. MDCT and $3 D$ Workstations. Springer Science+Business Media,Inc., China.

Michael F.Mc Nitt-Gray. 2002. Trade offs in CT Image Quality and Dose, AAPM/RSNA. Imaging and Therapeutic Technology

Nagel, H.D. 2004. Multislice CT Technology, Germany. www.multislice.com, akses 2 Juni 2013.

Nesseth, Roland. 2000. Prosedure and Documentation for CT and MRI. McGraw-Hill Medical Publishing Division, Kansas.

Pearce, Evelyne. 2001. Anatomy dan Fisiologi untuk Paramedis. Gramedia, Jakarta.

Rasad, S. 2009. "Radiologi Diagnostik", Cetakan kelima. Balai Penerbit FKUI, Jakarta.

Reiser,M.F., Becker,C.R., Nikolau,K., Glazer,G. 2009. Multislice CT, $3^{\text {rd }}$ revised edition. Springer-Verlag Berlin Heidelberg, Germany.
Robert A. Parry, MS, Sharon A. Glaze, MS and Benjamin R,Archer, PhD 1999. Typical Patient Radiation Doses in Diagnostic Radiology, AAPM/RSNA. Imaging and Therapeutic Technology

Sarkar. M.R.AY, dkk. 2005. Estimating of Patient Dose in Abdomen-Pelvis CT Exam as a Function of Scan Technique in Single and Multi Slice Spiral CT by Monte Carlo Method.

Seeram E. 2001. Computed Tomography: physical principles clinical applications, and quality control, Second edition. WB Saunders Company, Philadelphia. 